Western North American Naturalist 68(1), (C) 2008, pp. 103-106

\title{
COMPARISON OF DESERT VALVATA SNAIL GROWTH AT THREE DENSITIES OF THE INVASIVE NEW ZEALAND MUDSNAIL
}

\author{
Steven Lysne ${ }^{1,2}$ and Peter Koetsier ${ }^{1}$
}

ABSTRACT.-Invasive species are of concern to natural resource managers and conservation biologists. The New Zealand mudsnail (Potamopyrgus antipodarum) has invaded many freshwaters of the western United States with unknown consequences on the native benthic invertebrate fauna. We conducted a laboratory investigation to determine if mudsnails affected the growth of the desert valvata snail (Valvata utahensis), a species native to the Snake River in southern Idaho. Results indicated that increasing densities of mudsnails limited the growth rate and absolute growth of the desert valvata. We suggest that absolute growth is a better metric than growth rate for comparing snail species and assessing interactions between them.

Key words: desert valvata, mudsnail, invasive species, snail growth.

The New Zealand mudsnail (Potamopyrgus antipodarum) is an invasive freshwater snail in the family Hydrobiidae. The species was first observed in North America in the Snake River of southern Idaho in the 1980s and has since spread to several western states (Richards et al. 2001). The species is of concern to natural resource managers because it can reach extremely high densities (Hall et al. 2003), has high tolerances to physical stressors (Richards 2004, Lysne and Koetsier 2006a), and has a very high invasion potential owing to its viviparous reproductive strategy (Strayer 1999, Richards 2004). The desert valvata snail (Valvata utahensis) is an endangered freshwater snail in the family Valvatidae and is native to the Snake River in Idaho. We conducted an investigation in the laboratory to determine if the growth of $V$. utahensis individuals was affected by increasing densities of $P$. antipodarum. Specifically, we tested the hypotheses that there are no differences in growth rate $\left(\mathrm{H}_{1}\right)$ or absolute growth $\left(\mathrm{H}_{2}\right)$ of $\mathrm{V}$. utahensis at 3 densities of $P$. antipodarum.

Growth chambers were constructed of clear plastic centrifuge tubes $(27 \mathrm{~mm}$ diameter). The closed end of the centrifuge tube was cut off, filed, and lightly sanded such that the resulting open-ended tube was approximately $9 \mathrm{~cm}$ long with an inside surface area of approximately $0.008 \mathrm{~m}^{2}$. The inside of each chamber was scoured to create a rough surface for algae attachment. Both ends of chambers were cov- ered with $0.9-\mathrm{mm}$ mesh fiberglass screen and secured with rubber bands. Slack in the fiberglass screen was removed to create a complete barrier to snail escape. Growth chambers were placed horizontally in a weighted test-tube rack and placed in the bottom of a 20 -L aquarium. The aquarium was aerated and the water was filtered. Average temperature was $21.8^{\circ} \mathrm{C}$ $(s=1.0)$ and dissolved oxygen (DO) was $6 \mathrm{mg}$ $\cdot \mathrm{L}^{-1}(s=0.7)$. Food for snails was provided by immersing growth chambers in an algal slurry (Alga-grow ${ }^{\circledR}$ freshwater algae Navicula sp. and Synedra sp., Carolina Biological Supply Co., Burlington, NC) for approximately 3 weeks before use. Individual snails were transferred to new growth chambers each week. We neither attempted to mimic resource availability in situ nor to estimate it in growth chambers. Water chemistry information was collected periodically (data available upon request), and pulverized organically grown eggshells were added monthly as a source of calcium for shell growth (Voss et al. 2001). A fluorescent grow lamp was placed over the aquarium, and photoperiod was manipulated each week to match changing ambient daylight hours (i.e., MayJune 2002). The experiment lasted 94 days.

Snails were chosen haphazardly from general holding tanks; measured to the nearest $0.01 \mathrm{~mm}$ with an ocular micrometer (mounted on a compound microscope) from the apical whorl, across the shell axis, to the distal aperture margin; and then randomly assigned to 1

${ }^{1}$ Department of Biology, Boise State University, 1910 University Avenue, Boise, ID 83725.

${ }^{2}$ E-mail: stevenlysne@mail.boisestate.edu 


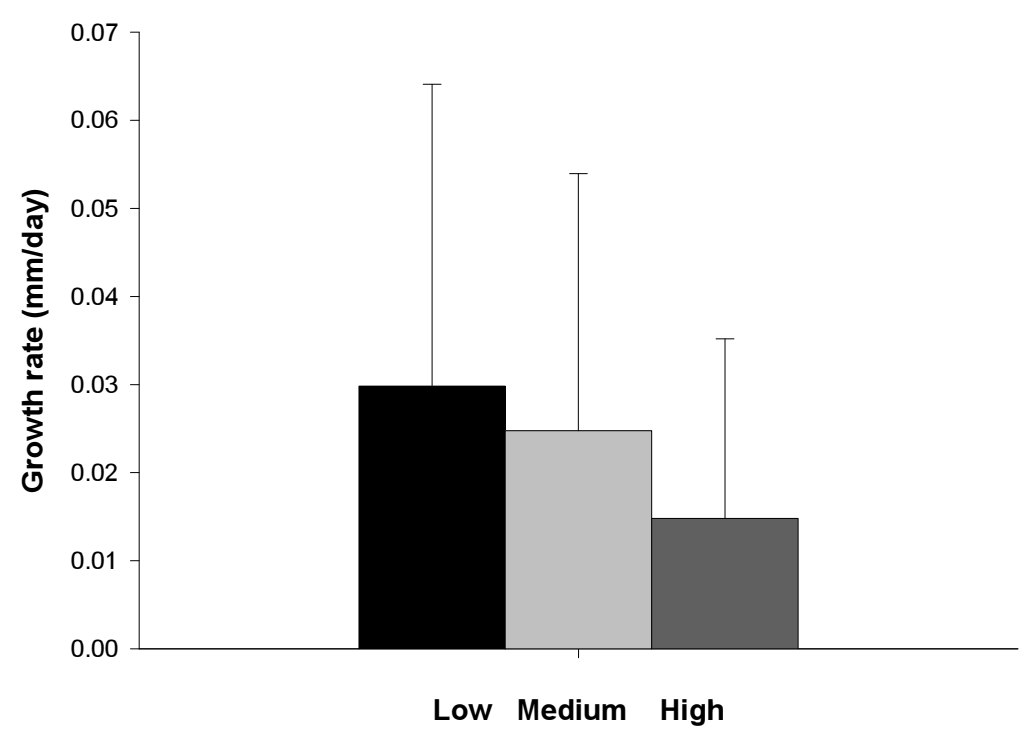

Fig. 1. Mean growth rates of Valvata utahensis through 53 days at low, medium, and high densities of Potamopyrgus antipodarum from laboratory studies. Bars represent 1 standard deviation. Differences were not significant $\left(F_{2,6}=4.04\right.$, $P=0.08)$.

of 3 density treatments. The average starting size of $V$. utahensis was $2.33 \mathrm{~mm}(s=0.47$ $\mathrm{mm})$ and $P$. antipodarum was $4.32 \mathrm{~mm}(s=$ 1.04). We used large adult mudsnails $(>4 \mathrm{~mm})$ because we assumed that mature snails at the top of a growth curve (i.e., not exhibiting the rapid growth of smaller individuals) would provide a similar degree of interaction across individuals in different treatments. Potamopyrgus antipodarum densities were chosen at fixed intervals within the range of densities found in nature (Zaranko et al. 1997, Richards et al. 2001, Weigel 2002). Valvata utahensis density was chosen based on field collections in Idaho (Lysne 2003) and was kept constant $\left(240\right.$ individuals $\left.\cdot \mathrm{m}^{-2}\right)$ in each treatment. Experimental treatments consisted of mudsnails at (1) low density (120 individuals $\cdot \mathrm{m}^{-2}$ ), (2) medium density $\left(240\right.$ individuals $\left.\cdot \mathrm{m}^{-2}\right)$, and (3) high density (500 individuals $\cdot \mathrm{m}^{-2}$ ). These densities corresponded to V. utahensis:P. antipodarum ratios in growth chambers of 2:1 in the low density treatment, 1:1 in the medium density treatment, and 1:2 in the high density treatment. We used 3 replicates for each density treatment. Snails were removed every 7-10 days and measured as discussed above; moribund individuals were not replaced. The 2 response variables were the average growth rate of individuals in each density treatment and the average total growth of individuals from each treatment. Growth rate was calculated following Lysne and Koetsier (2006b). Total growth for each treatment was calculated using the following equations:

$$
\text { Total growth }=L_{\mathrm{e}}-L_{\mathrm{i}}
$$

where $L_{\mathrm{e}}=$ the average ending length of individuals in a treatment and $L_{\mathrm{i}}=$ the average initial length of individuals in a treatment. Both $L_{\mathrm{e}}$ and $L_{\mathrm{i}}$ were calculated as

$$
\left.\sum\left[\left(L_{\mathrm{a}}+L_{\mathrm{b}}\right) / n\right)\right] / N,
$$

where $L_{\mathrm{a}, \mathrm{b}}=$ length of individual snails in a growth chamber, $n=$ number of $V$. utahensis in each growth chamber (2), and $N=$ number of replicates in each treatment (3). To limit the number of endangered snails used, we did not perform a control (i.e., V. utahensis at 240 individuals $\cdot \mathrm{m}^{-2}$ and $P$. antipodarum at 0 individuals $\cdot \mathrm{m}^{-2}$ ) but instead compared our results to laboratory growth rates estimated by Lysne and Koetsier (2006b).

Significant mortality began to occur in all treatments and replicates after about 70 days (i.e., $72 \%$ at day 94 ). Thus, we only analyzed observations to 53 days, when all individuals remained alive. Our experimental design, therefore, was a $3 \times 8$ factor factorial. Growth rates were tested for differences using repeated 


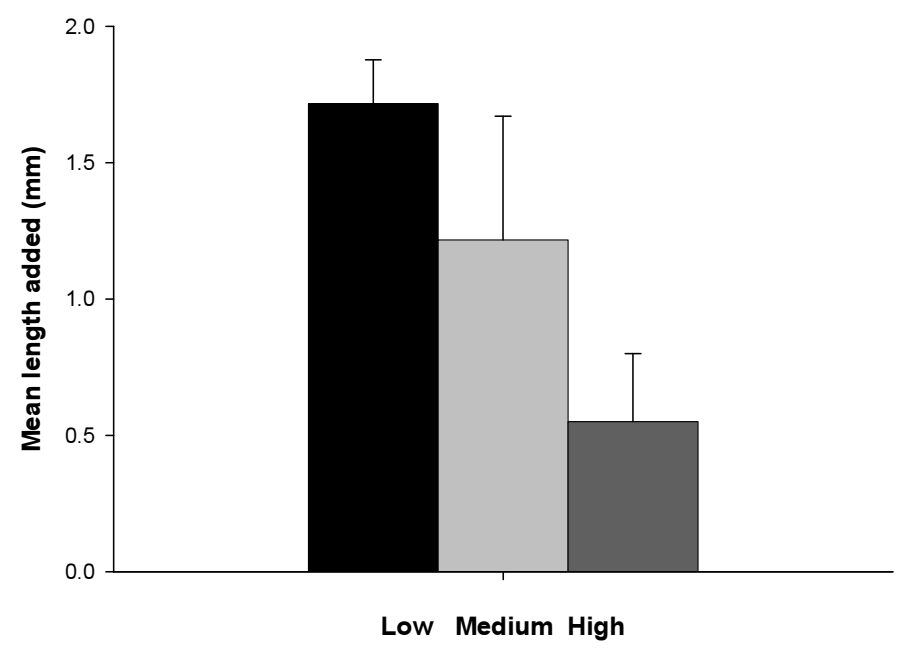

Fig. 2. Mean shell length added by Valvata utahensis over 53 days of observation at low, medium, and high densities of Potamopyrgus antipodarum. Bars represent 1 standard deviation. Results from 1-way ANOVA were significant $\left(F_{2,6}=\right.$ $10.48, P=0.04)$. Post hoc analyses revealed significant differences between the low and high density only.

measures ANOVA. Total shell length added during the study was compared using 1-way ANOVA with multiple Student's $t$ tests in the least-square means procedure for all pairwise comparisons. Data met normality and independence assumptions; therefore, no transformations were needed. All analyses were conducted with SAS statistical software (SAS 2001). Voucher specimens are at the Orma J. Smith Museum of Natural History, Caldwell, Idaho (ALBRCIDA 00038038-00038051).

Average growth rates did not differ significantly among treatments, nor was there a significant interaction between treatments and time (Fig. 1). There was, however, a significant difference observed over time. This is likely due to the relatively higher growth rates of snails in most treatments at the beginning of the test, when individuals are small, compared to the end of the test, when individuals are larger. Although differences were not significant, there was a trend toward higher growth rates in both the medium and low mudsnail density treatments compared to the high mudsnail density treatment over the 53 days of observation, and this trend may be biologically significant. Interestingly, V. utahensis growth rates at high mudsnail density were comparable to those growth rates found in previous investigations with V. utahensis only (Lysne and Koetsier 2006b). Growth rates in the low and medium density treatments are the greatest reported to date for $V$. utahensis. Recent work indicates that low to medium densities of mudsnails may facilitate the growth of Taylorconcha serpenticola through their grazing actions or changes in nutrient availability (Richards 2004). Another explanation for the high growth rates is that the algal slurry we used resulted in an excess of a highly nutritious food source (Dorgelo and Leonards 2001).

Average absolute growth of individuals was significantly different between density treatments (Fig. 2). These results suggest that there may be an effect of increasing P. antipodarum densities on the growth of $V$. utahensis in the laboratory. Even though laboratory studies often lack relevance to natural environs, the temperature we used is typical of the Snake River in summer (Weigel 2002), both species live sympatrically in the Snake River of Idaho, and in some reaches, $P$. antipodarum can reach densities far greater than those used in this study (Richards et al. 2001, Hall et al. 2003). Results also suggest that absolute growth may be a better metric for determining interactions between snail species because instantaneous rates of growth vary widely and are dependent on ontogenetic factors. We acknowledge, however, that absolute growth is dependent on the time frame of a particular investigation and that expressing growth rates in terms of millimeters per day is better suited for comparing results across a wide range of studies. Simply reporting 
both absolute growth and growth rate, as we have done here, resolves this concern. Future work should address growth rates and interactions among these species in a natural environment.

Our work was funded by the U.S. Fish and Wildlife Service and the U.S. Bureau of Reclamation. We thank R. Hershler for species identifications and D.C. Richards for discussions on experimental design. D. Strayer and 2 anonymous reviewers provided comments that helped us to greatly improve this manuscript.

\section{Literature Cited}

Dorgelo, J., And P.E.G. Leonards. 2001. Relationship between $\mathrm{C} / \mathrm{N}$ ratio of food types and growth rate in the snail Potamopyrgus jenkinsi (E.A. Smith). Journal of the North American Benthological Society 20:60-67.

Hall, R.O., M.C. VAnderloop, and M.F. Dybdahl. 2003. Exotic snails dominate nitrogen and carbon cycling in a highly productive stream. Frontiers in Ecology and the Environment 1:407-411.

Lysne, S., And P. Koetsier. 2006a. Experimental studies on habitat preference and tolerances of three species of snails from the Snake River of southern Idaho, U.S.A. American Malacological Bulletin 21:77-85.

. 2006b. Growth rate and thermal tolerance of two endangered Snake River snails. Western North American Naturalist 66:230-238.

Lysne, S.J. 2003. The life history and ecology of two endangered Snake River gastropods: Utah valvata
(Valvata utahensis; Call) and Idaho springsnail (Pyrgulopsis idahoensis: Pilsbry). Master's thesis, Boise State University, Boise, ID. 103 pp.

Richards, D.C. 2004. Competition between the threatened Bliss Rapids snail, Taylorconcha serpenticola (Hershler et al.) and the invasive, aquatic snail Potamopyrgus antipodarum (Gray). Doctoral dissertation, Montana State University, Bozeman. 156 pages.

Richards, D.C., L.D. Cazier, and G.T. Lester. 2001. Spatial distribution of three snail species, including the invader Potamopyrgus antipodarum, in a freshwater spring. Western North American Natualist 61: $375-380$.

[SAS] SAS Institute, InC. 2001. Version 8.0. SAS Institute, Inc., Cary, NC.

Strayer, D.L. 1999. Effects of alien species on freshwater mollusks in North America. Journal of the North American Benthological Society 18:74-98.

Voss, B., A. Utecht, And W. Wünnenberg. 2001. The dependence of thermopreferendum in Helix pomatia L. on air temperature. Journal of Thermal Biology 26:155-158.

WEIGEL, D. 2002. Research, monitoring and surveys for snails protected under the Endangered Species Act in the upper Snake River, Idaho. Technical report submitted to the U.S. Fish and Wildlife Service, Boise, ID. $28 \mathrm{pp}$.

Zaranko, D.T., D.G. Farara, and F.G. Thompson. 1997. Another exotic mollusk in the Laurentian Great Lakes: the New Zealand native Potamopyrgus antipodarum (Gray, 1843) (Gastropoda: Hydrobiidae). Canadian Journal of Fisheries and Aquatic Sciences 54:809814.

Received 11 January 2007 Accepted 27 August 2007 